\title{
Dapsone can be a new treatment option for reducing the detrimental effect of priapism
}

\author{
๑Engin Kölükçü̈ ${ }^{1}$, @Bekir Süha Parlaktaş${ }^{1}$, @Nihat Uluocak ${ }^{1}$, @Faik Alev Deresoy², @Muzaffer Katar ${ }^{3}$, \\ (1) Velid Unsal ${ }^{4}$ \\ ${ }^{1}$ Gaziosmanpaşa University, Faculty of Medicine, Department of Urology, Tokat, Turkey \\ ${ }^{2}$ Gaziosmanpaşa University, Faculty of Medicine, Department of Pathology, Tokat, Turkey \\ ${ }^{3}$ Gaziosmanpaşa University, Faculty of Medicine, Department of Biochemistry, Tokat, Turkey \\ ${ }^{4}$ Mardin Artuklu University, Faculty of Health Sciences and Central Research Laboratory, Mardin, Turkey
}

Cite this article as: Kölükçü E, Parlaktaş BS, Uluocak N, Deresoy FA, Katar M, Unsal V. Dapsone can be a new treatment option for reducing the detrimental effect of priapism. J Health Sci Med 2021; 4(6): 800-808.

\begin{abstract}
Aim: This study aims to analyze the effect of dapsone against ischaemia-reperfusion injury on corporal tissue in a model of induced-priapism in rats.

Material and Method: A total of 24 rats were randomized into three groups. Group 1 was defined as the control group. Ischaemia-reperfusion injury was evaluated following the priapism model in Group 2. Group 3 had similar procedures to the rats in Group 2. Group 3 additionally had $12.5 \mathrm{mg} / \mathrm{kg}$ dapsone administered intraperitoneally 30 minutes after priapism.

Results: Biochemical analysis of blood indicated a significant increase in Group 3 in terms of superoxide dismutase (SOD), glutathione peroxidase (GSH-Px) activity and total antioxidant status (TAS) values compared with Group 2 (p:0.002, p:0.029 and p:0.009, respectively). The highest values of malondialdehyde (MDA), protein carbonyl (PC) and total oxidant status (TOS) were recorded in Group $2(\mathrm{p}<0.001)$. Interleukin 1beta (IL-1beta), Interleukin 6 (IL-6) and tumor necrosis factor alpha (TNF alpha) levels were found to be significantly decreased in Group 3 compared with Group 2 (p:0.022, p:0.049 and $\mathrm{p}<0.001$, respectively). Direct microscopic evaluation determined an improvement in inflammation, edema, desquamation and vasocongestion scores in Group 3 compared to Group 2 ( $\mathrm{p}<0.05)$.

Conclusion: Dapsone has a protective effect on ischaemia-reperfusion injury in corporal tissue.

Keywords: Dapsone, priapism, ischaemia reperfusion injury, treatment
\end{abstract}

\section{INTRODUCTION}

Priapism is an urgent urologic pathology defined by full or partial tumescence lasting longer than 4 hours without sexual stimulation (1). Priapism is characterised by three different categories as ischaemic (low flow, veno-occlusive), non-ischaemic (high flow, arterial) and stuttering (intermittent, recurrent ischaemic) priapism. Ischaemic priapism is the most common form of priapism that accounts for $95 \%$ of the cases (2). It is predicted that the incidence of ischaemic priapism is between $0.34-1.5$ per 100,000 person in a year (3). Basic pathophysiology of ischaemic priapism includes venous obstruction, and stasisin penilecorpuscavernosa. Thisclinicalpresentation, which is known as, penile compartment syndrome, poses a threat for the vitality of penile tissues by developing anoxic, hypercarbic, acidic and glucopenic environment (2). Reoxygenation of penile corpus cavernosa is essential for restoration of normal sexual functioning. On the other hand, after priapism is corrected with the effective treatment approaches, ischaemia-reperfusion injury occurs which leads to severe cellular damage paradoxically following the revascularization. Several different pathways are involved in the pathophysiology of ischaemia-reperfusion injury. The basic mechanism can be explained by reactive oxygen species (ROS) which are produced rapidly when dense molecular oxygen enters into the cell. ROS, which are abundant in the environment during the ischaemia-reperfusion period, render natural antioxidant mechanisms ineffective. Critically elevated levels of ROS lead to a severe tissue destruction by interacting with several vital units such as membrane lipids, macro proteins and nucleic acids (4). In this regard, keeping the ischaemia-reperfusion injury 
due to termination of priapism at the lowest levels holds critical importance for the cases to maintain a healthy sexual life afterwards. Different experimental priapism models of previous years has focused that many different molecules were used to minimise ischaemia-reperfusion injury in penile corpus cavernosa (4-9).

Dapsone (4,4'-diaminodiphenylsulfone) is a derivative of aniline that belongs to the group of synthetic sulfones exhibiting antibacterial and antiparasitic properties. It inhibits the growth of microorganisms by suppressing folic acid synthesis in a competitive manner with paraaminobenzoate, which is a critical substrate of dihydropteroate synthase. Since 1940's, it has been included in the multidrug therapy protocol for leprosy treatment by World Health Organization (10). Additionally, different infectious diseases are also preferred in Malaria disease and Pneumocystis carinii pneumonia which is manifested in immune-suppressive patients (11). Apart from its antimicrobial properties, Dapsone shows an anti-inflammatory activity by blocking the leukocyte enzyme myeloperoxidase (10). It also activates the scavenging enzyme system and inhibits apoptosis $(12,13)$. Recent studies have revealed that dapsone can be used effectively and safely in infective pathologies, as well as in minimizing tissue damage by exhibiting anti-inflammatory, anti-apoptotic and antioxidant properties against oxidative stress in many different systems such as skin, kidney, testis, heart, brain and spinal cord (11-18).

The aim of the present study is to determine the possible protective effect of dapsone against ischaemiareperfusion injury in penile corpus cavernosa. According to our knowledge, this is the first experimental study in the English literature administering dapsone to rats with an induced-priapism model.

\section{MATERIAL AND METHOD}

After obtaining approval from the Tokat Gaziosmanpaşa University Animal Studies Ethics Committee (Date: 08.04.2021, Decision No: 2021-HADYEK-06), a total of twenty four male Wistar albino rats, 7-7.5 months old and weighing $310-350 \mathrm{~g}$, were used in this study. The rats were handled in the laboratory according to institutional guidelines as well as the Guide for Care and Use of Laboratory Animals of the National Research Council. The animals were housed under standard vivarium conditions in a climate-controlled room $\left(18-22^{\circ} \mathrm{C}\right.$, 40-60\% humidity, and 12-h light/dark cycle), with free access to water and standard rodent chow. Experimental animals were divided into three groups. Group 1 was defined as the control group. Group 2 was designed as the ischaemia-reperfusion group. Group 3 included the treatment group.
All surgical procedures were performed in sterile conditions and under the appropriate depth of anesthesia. To this aim, ketamine $1 \mathrm{mg} / \mathrm{kg}$ xylazine and $50 \mathrm{mg} / \mathrm{kg}$ ketamine were used intraperitoneally.

Group 1 rats were sham group and only penectomy was performed in this group. Penile tissues were sent to pathology laboratory for histopathological examination. Additionally, blood samples were taken from inferior vena cava for biochemical analysis.

A model of priapism was performed for rats in Group 2. This model was implemented using the method previously defined by Ciftci et al (8). Accordingly, constriction bands were prepared by dividing $16 \mathrm{Fr}$ silicone foley catheter into straight pieces with an approximate length of $2 \mathrm{~mm}$. A $50 \mathrm{cc}$ syringe was used as vacuum erection device on the penises of rats. A full penile erection was achieved by applying negative pressure with the syringe. Afterwards, a priapism model was constructed by placing constriction bands at the root of the penis (Figure 1) $(6,8)$. Constriction bands were removed after maintaining priapism for an hour in total. Rats rested for an hour for the evaluation of ischaemia-reperfusion injury (8). Finally, penectomy was performed for histopathological examination and blood samples were obtained from their inferior vena cava for biochemical analysis.

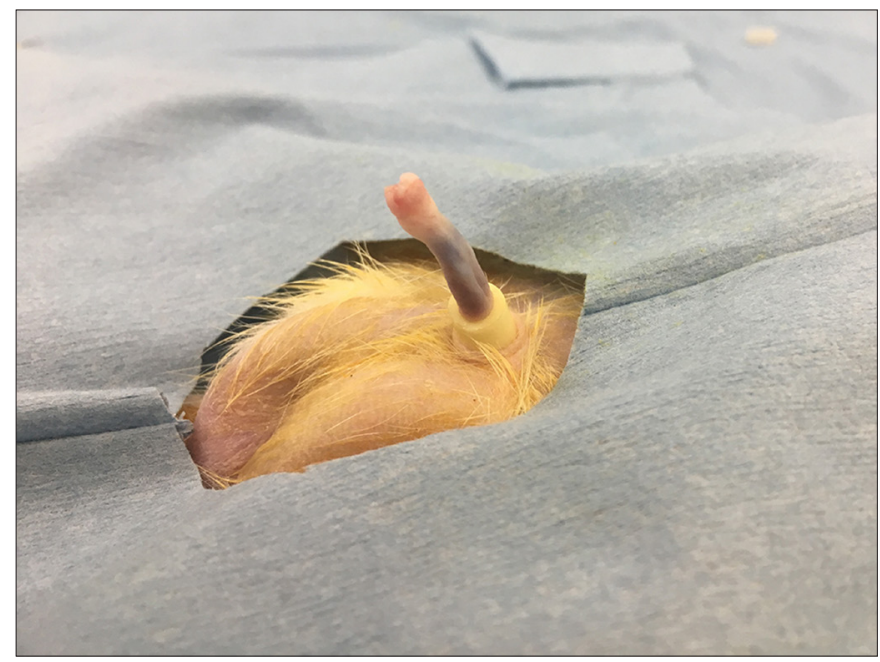

Figure 1. Experimental priapism model in rat

Group 3 had similar procedures to the rats in Group 2. Group 3 additionally had a single dose of dapsone (12.5 $\mathrm{mg} / \mathrm{kg}$ ) administered intraperitoneally 30 minutes after priapism $(11,13)$. Dapsone was suspended in $4.5 \% \mathrm{v} / \mathrm{v}$ poly (ethylene glycol)/water. Ninety minutes after the administration of dapsone, a blood sample was taken from the inferior vena cava by applying penectomy. Dapsone were provided from Sigma-Aldrich (CAS Number: 80-08-0). 
At the end of the experiment, cervical dislocation was applied to all rats and their vital functions were terminated.

\section{Biochemical Evaluation}

\section{Measurement of Malondialdehyde (MDA) Level}

MDA is the latest product of lipid peroxidation and is a frequently used marker as an indicator of oxidative stress. MDA reacts in an acidic environment under high temperatures with thiobarbituric acid (TBA), forming a pink compound. The optical density of this compound was measured at a wavelength of $532 \mathrm{~nm}$ and the MDA level was calculated. The results were measured using a standard graph prepared with standard 1,1,3,3-tetraethoxypropane serial dilutions. MDA level was expressed as $\mu \mathrm{mol} / \mathrm{L}$ (19).

\section{Measurement of Protein Carbonyl (PC) Level}

Evidence of oxidative stress manifests an increase in reactive carbonyl groups in protein oxidation. PC groups were analyzed and assessed by spectrophotometrical means at $370 \mathrm{~nm}$ based on the principle that hydrazine occurs as a result of the reaction of carbonyl groups of proteins with 2.4 Dinitrophenylhydrazine (DNPH) (20). PC level was expressed as $\mathrm{nmol} / \mathrm{ml}$.

\section{Measurement of Superoxide Dismutase (SOD) Activity}

The principle of this experiment is based on the formation of violet-colored formazan compound via the superoxide radical, which is created through xanthinxanthin oxidase system, by reducing the nitro-blue tetrazolium (NBT) compound in the environment. This compound gives maximum absorption at a wavelength of $560 \mathrm{~nm}$ on a spectrophotometer. In the serum added to the reaction environment, the enzyme SOD removes the formed superoxide radicals from the environment, preventing the reduction of NBT in direct proportion to its activity. Enzyme activity was calculated by comparing the absorption value found by adding SOD to the environment with the absorbent of the blind experiment in which the enzyme was not added (21). The SOD activity unit was expressed as U/L.

\section{Measurement of Glutathione Peroxidase (GSH-Px) Activity}

The glutathione reductase enzyme downgrades the upgraded GSH while at the same time increasing nicotinamide adenine dinucleotide phosphate (NADPH) and transforming it into nicotinamide adenine dinucleotide (NADP). It provides NADPH absorption at a wavelength of $340 \mathrm{~nm}$ on the spectrophotometer. The reduction in absorption due to conversion to NADP allows measurement of GSH-Px activity (22). GSH-Px activity unit was expressed as U/L.
Measurement of Tumour Necrosis Factor-Alpha (TNFalpha), Interleukin-1 Beta (IL-1 Beta), Interleukin-6 (IL-6) Levels

The kits were supplied from Atlas Biotechnology (Ankara, Turkey). TNF- alpha (Cat.No E0764Ra), IL-1 beta (Cat.No E0119 Ra), and IL6 (Cat.No E0135Ra) levels measured in serums using ELISA kits according to the instructions of manufacturers. Measurement was carried out with Multiskan $^{\text {tw }}$ FC Microplate Photometer device. TNF- alpha and IL-1 beta were expressed as pg/ $\mathrm{ml}$ while IL-6 ng/ml.

\section{Measurement of Total Antioxidant Status (TAS) and Total Oxidant Status (TOS) Level}

TAS and TOS levels were measured using a novel automated colorimetric method developed by Erel $(23,24)$. TAS were expressed as mmol Trolox equivalent/L while TOS $\mu \mathrm{mol} \mathrm{H}_{2} \mathrm{O}_{2}$ equivalent/L.

\section{Histopathological Evaluation}

The penile tissues of rats were kept in $10 \%$ buffered formalin solution for 2 days. Samples were cut by $4 \mu \mathrm{m}$ by microtome and stained with haematoxylin and eosin solutions following the grossing and tissue preparation. Tissue slides were examined via upright light microscope (Nikon Eclipse E600). Tissue slides were assessed and scored in the categories of vasocongestion, inflammation, desquamation and edema. A semiquantitative scoring system was employed for scoring histopathological alterations in parallel to the one used by Senturk et al. These parameters were scored between 0 and 3 as follows: 0 : normal, 1: mild, 2: moderate and 3: severe (25).

\section{Statistical Method}

Statistical analysis in this study were conducted using the SPSS (SPSS Inc., Chicago, IL, USA) package program. Descriptive statistics were presented as mean \pm standard deviation and median (min-max) depending on the data's normal distribution. Normality distribution of the data was evaluated using the Shapiro-Wilk test. Levene's test was used to test the homogeneity of variances. ANOVA was used for normally distributed data and KruskalWallis test was used for non-normally distributed data in continuous variable comparisons between three independent groups. In order to determine the different groups after ANOVA analysis, Tukey post-hoc test was used when the assumption of homogeneity of variances was met and Games-Howell post-hoc test was used when the assumption of homogeneity of variances was not met. After the Kruskal-Wallis test, the Mann-Whitney U test with Bonferroni correction post-hoc test was used to determine the different groups. $\mathrm{P}$ values $<0.05$ were considered statistically significant. 


\section{RESULTS}

Our histopathological results are documented in Table 1. When penile tissue samples in Group 2 were examined in detail, it was determined that inflammation, edema, desquamation and vasocongestion scores were extremely negatively affected compared to Group $1(\mathrm{p}<0.001)$. The mean inflammation score in Group 3 was calculated as $0.88 \pm 0.354$ and inflammation scores decreased dramatically compared to Group 2 (p: 0.031) (Figure 2). No penile tissue samples in Group 3 had severe edema and vasocongestion. These scores were significantly lower in Group 3 than in Group 2 (p:0.018 and p:0.037, respectively) (Figure 3 and Figure 4). In Group 2, the desquamation score was observed as $1.88 \pm 0.354$. This value was significantly higher than Group 3 (p:0.038) (Figure 5).

Our serum biochemical analysis results are detailed in Table 2. In Group 2, MDA and PC levels, the latest products of lipid peroxidation and protein oxidation, were calculated as $1.53 \pm 0.33$ and $606.4 \pm 59.06$. These values were recorded as considerably higher than Group 1 (p:0.001 and $\mathrm{p}<0.001$ respectively). In Group 3, it was noted that there was a dramatic decrease in MDA and PC levels compared to Group 2 (p:0.003 and p:0.015, respectively). The levels of the pro-inflammatory cytokines including IL-1 beta, IL-6, and TNF-alpha were observed to be highest in Group $2(\mathrm{p}<0.001)$. On the other hand, serum samples of rats in Group 3 showed a significant decrease in these inflammatory markers ( $\mathrm{p}: 0.022, \mathrm{p}: 0.049$ and $\mathrm{p}<0.001$, respectively). TOS levels were recorded as $11.2 \pm 1.78$ in Group 2. This level was quite high compared to Group $1(\mathrm{p}<0.001)$. In Group 3 , the TOS level was $8.37 \pm 1.58$ and these values were recorded as significantly lower than Group 2 (p:0.002). When the antioxidant enzyme level is analyzed, SOD and GSH-px Px activity were significantly higher in Group 3 compared to Group 2 (p:0.002 and p:0.029, respectively). Similarly, the TAS level was noted as $1.39 \pm 0.30$ in Group 3, which was recorded as significantly increased compared to Group 2 (p:0.009).
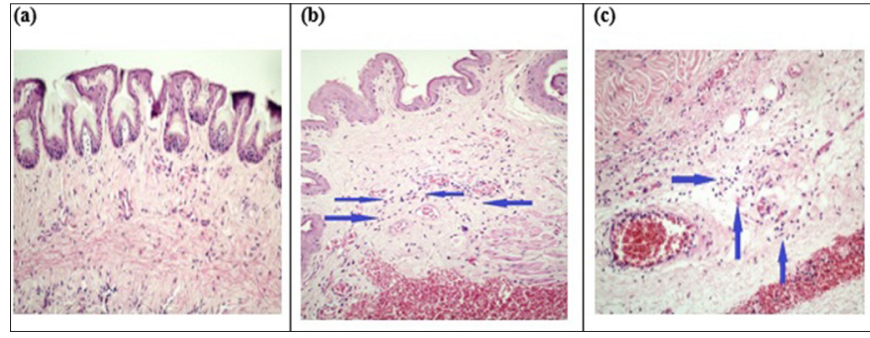

Figure 2. Inflammation between groups a. No inflammation in Group 1. b. Moderate inflammation foci accompanying congested vascular structures and hemorrhage areas in Group 2. c. Local and mild inflammation in Group 3. Magnification is x10 for all images, blue arrows indicate inflammatory cells and neutrophills.
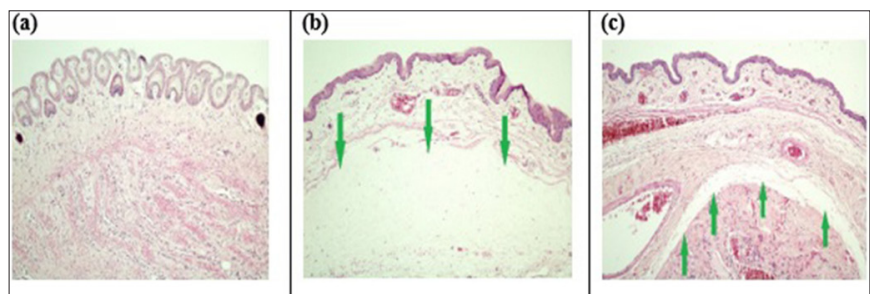

Figure 3. Evaluation of edema between groups. a. No edema in Group 1. b. Extensive edema in Group 2. c. Mild and focal edema in Group 3. Green arrows indicate edematous areas, magnification is x10 for all images.
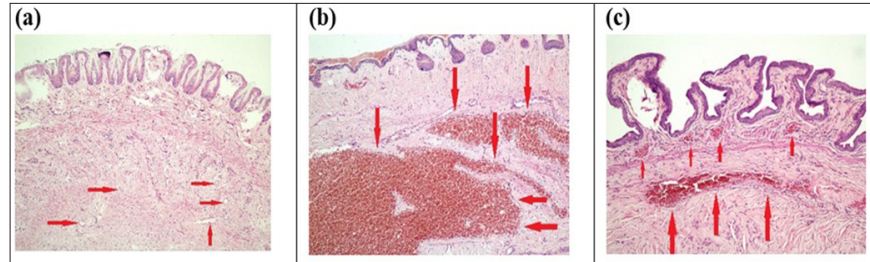

Figure 4. Comparison of vasocongestion between groups. a Only normal caliber vascular structures (red arrows), scored as no vasocongestion in Group 1. b. Extensive vasocongestion and focal haemorrhage in Group 2 (red arrows). c. Vasocongestion of medium and small sized vascular structures in Group 3 (red arrows). Microscopic magnification is x10 for all photos.
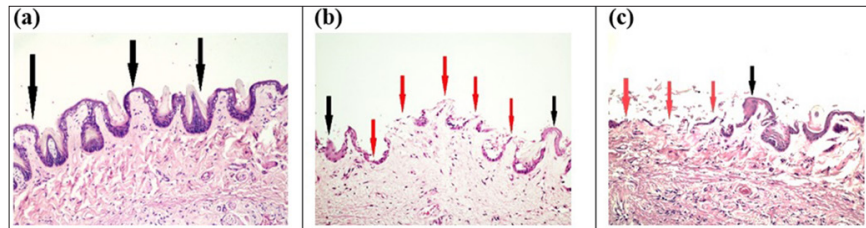

Figure 5. Desquamation alterations are shown. a. No desquamation in Group 1. b. Medium desquamation occurring in Group 2. c. Focal and mild desquamation detected in Group 3 Black arrows indicate normal thickness epithelium, whereas red arrows show desquamated areas. Magnification is x 20 for both images.

\begin{tabular}{|c|c|c|c|c|c|c|}
\hline & Groups & $\mathbf{N}$ & Mean \pm SD & Median (min-max) & $P$ values & Post-hoc $P$ values \\
\hline \multirow{3}{*}{ Inflammation } & 1 & 8 & $0.25 \pm 0.463$ & $0(0-1)$ & \multirow{3}{*}{$<0.001^{\text {a* }}$} & $1-2^{\mathrm{b}}:<0.001^{\star}$ \\
\hline & 2 & 8 & $1.88 \pm 0.354$ & $2(1-2)$ & & $1-3^{b}: 0.327$ \\
\hline & 3 & 8 & $0.88 \pm 0.354$ & $1(0-1)$ & & $2-3^{\mathrm{b}}: 0.031^{\star}$ \\
\hline \multirow{3}{*}{ Desquamation } & 1 & 8 & $0.13 \pm 0.354$ & $0(0-1)$ & \multirow{3}{*}{$<0.001^{\text {ax }}$} & $1-2^{\mathrm{b}}:<0.001^{*}$ \\
\hline & 2 & 8 & $1.88 \pm 0.354$ & $2(1-2)$ & & $1-3^{\mathrm{b}}: 0.422$ \\
\hline & 3 & 8 & $0.75 \pm 0.707$ & $1(0-2)$ & & $2-3^{\mathrm{b}}: 0.038^{\star}$ \\
\hline \multirow{3}{*}{ Edema } & 1 & 8 & $0.38 \pm 0.518$ & $0(0-1)$ & \multirow{3}{*}{$<0.001^{\text {a* }}$} & $1-2^{\mathrm{b}}:<0.001^{\star}$ \\
\hline & 2 & 8 & $2.88 \pm 0.354$ & $3(2-3)$ & & $1-3^{\mathrm{b}}: 0.312$ \\
\hline & 3 & 8 & $1.13 \pm 0.354$ & $1(1-2)$ & & $2-3^{b}: 0.018^{\star}$ \\
\hline \multirow{3}{*}{ Vasocongestion } & 1 & 8 & $0.5 \pm 0.535$ & $0.5(0-1)$ & \multirow{3}{*}{$<0.001^{\text {a* }}$} & $1-2^{\mathrm{b}}:<0.001^{*}$ \\
\hline & 2 & 8 & $2.75 \pm 0.463$ & $3(2-3)$ & & $1-3^{\mathrm{b}}: 0.249$ \\
\hline & 3 & 8 & $1.38 \pm 0.518$ & $1(1-2)$ & & $2-3^{b}: 0.037^{*}$ \\
\hline
\end{tabular}




\begin{tabular}{|c|c|c|c|c|c|c|}
\hline & Groups & $\mathbf{N}$ & Mean \pm SD & Median (min-max) & $P$ values & Post-hoc $P$ values \\
\hline \multirow{3}{*}{$\begin{array}{l}\text { GSH-px } \\
\text { (U/L) }\end{array}$} & 1 & 8 & $1030 \pm 141$ & $1002.5(832-1295)$ & \multirow{3}{*}{$<0.001^{\text {a* }}$} & $1-2^{\mathrm{c}}:<0.001^{*}$ \\
\hline & 2 & 8 & $792.05 \pm 64.28$ & $807.6(706-887)$ & & $1-3^{c}: 0.087$ \\
\hline & 3 & 8 & $923.6 \pm 54.27$ & $920.1(845-1000)$ & & $2-3^{\mathrm{c}}: 0.029^{*}$ \\
\hline \multirow{3}{*}{$\begin{array}{l}\text { SOD } \\
(\mathrm{U} / \mathrm{L})\end{array}$} & 1 & 8 & $12.78 \pm 1.72$ & $12.89(9.22-15.2)$ & \multirow{3}{*}{$<0.001^{\text {a }}$} & $1-2^{c}:<0.001^{*}$ \\
\hline & 2 & 8 & $7.59 \pm 0.96$ & $7.34(6.34-8.96)$ & & $1-3^{c}: 0.001^{\star}$ \\
\hline & 3 & 8 & $10.03 \pm 0.89$ & $10.07(9.11-11.87)$ & & $2-3^{c}: 0.002^{\star}$ \\
\hline \multirow{3}{*}{$\begin{array}{l}\text { TAS } \\
\text { (mmol Trolox } \\
\text { equivalent/L) }\end{array}$} & 1 & 8 & $1.68 \pm 0.23$ & $1.75(1.3-2)$ & \multirow{3}{*}{$<0.001^{\text {a* }}$} & $1-2^{c}:<0.001^{*}$ \\
\hline & 2 & 8 & $0.98 \pm 0.17$ & $0.95(0.8-1.35)$ & & $1-3^{\mathrm{c}}: 0.063$ \\
\hline & 3 & 8 & $1.39 \pm 0.30$ & $1.37(1-1.8)$ & & $2-3^{\mathrm{c}}: 0.009^{*}$ \\
\hline \multirow{3}{*}{$\begin{array}{l}\text { PC } \\
(\mathrm{nmol} / \mathrm{ml})\end{array}$} & 1 & 8 & $477.47 \pm 22.72$ & $479.4(445.6-519.1)$ & \multirow{3}{*}{$<0.001^{\text {a* }}$} & $1-2^{c}:<0.001^{*}$ \\
\hline & 2 & 8 & $606.4 \pm 59.06$ & $615.1(500.12-682.5)$ & & $1-3^{\mathrm{c}}: 0.134$ \\
\hline & 3 & 8 & $528.5 \pm 60.82$ & $513.45(422.1-607.3)$ & & $2-3^{\mathrm{c}}: 0.015^{\star}$ \\
\hline \multirow{3}{*}{$\begin{array}{l}\text { MDA } \\
(\mu \mathrm{mol} / \mathrm{L})\end{array}$} & 1 & 8 & $0.79 \pm 0.07$ & $0.81(0.67-0.86)$ & \multirow{3}{*}{$<0.001^{\mathrm{a}^{*}}$} & $1-2^{\mathrm{d}}: 0.001^{*}$ \\
\hline & 2 & 8 & $1.53 \pm 0.33$ & $1.47(1-1.92)$ & & $1-3^{\mathrm{d}}: 0.001^{\star}$ \\
\hline & 3 & 8 & $0.95 \pm 0.06$ & $0.94(0.87-1.07)$ & & $2-3^{\mathrm{d}}: 0.003^{*}$ \\
\hline \multirow{3}{*}{$\begin{array}{l}\text { IL-1 beta } \\
(\mathrm{pg} / \mathrm{ml})\end{array}$} & 1 & 8 & $260.65 \pm 37.94$ & $265.4(205.3-312.1)$ & \multirow{3}{*}{$<0.001^{\text {b* }}$} & $1-2^{\mathrm{e}}: 0.001^{\star}$ \\
\hline & 2 & 8 & $367.47 \pm 33.94$ & $384.65(296.7-399.1)$ & & $1-3^{\mathrm{e}}: 1.000$ \\
\hline & 3 & 8 & $282.48 \pm 31.71$ & $287.7(214.4-321.2)$ & & $2-3^{\mathrm{e}}: 0.022^{*}$ \\
\hline \multirow{3}{*}{$\begin{array}{l}\text { IL-6 } \\
\text { (ng/ml) }\end{array}$} & 1 & 8 & $5.81 \pm 0.84$ & $5.92(4.22-7.2)$ & \multirow{3}{*}{$<0.001^{\mathrm{b}^{*}}$} & $1-2^{e}:<0.001^{*}$ \\
\hline & 2 & 8 & $11.26 \pm 2.19$ & $11.04(8.2-15)$ & & $1-3^{\mathrm{e}}: 0.206$ \\
\hline & 3 & 8 & $7.49 \pm 0.96$ & $7.94(5.56-8.21)$ & & $2-3^{\mathrm{e}}: 0.049^{*}$ \\
\hline \multirow{3}{*}{$\begin{array}{l}\text { TNF- alpha } \\
(\mathrm{pg} / \mathrm{ml})\end{array}$} & 1 & 8 & $313.03 \pm 43.15$ & $310.65(234.5-376.5)$ & \multirow{3}{*}{$<0.001^{\mathrm{a}^{*}}$} & $1-2^{c}:<0.001^{*}$ \\
\hline & 2 & 8 & $445.57 \pm 48.98$ & $439.45(376.2-522.1)$ & & $1-3^{\mathrm{c}}: 0.503$ \\
\hline & 3 & 8 & $337.96 \pm 38.79$ & $328.15(288.9-411)$ & & $2-3^{c}:<0.001^{*}$ \\
\hline \multirow{3}{*}{$\begin{array}{l}\text { TOS } \\
\left(\mu \mathrm{mol} \mathrm{H}_{2} \mathrm{O}_{2}\right. \\
\text { equivalent/L) }\end{array}$} & 1 & 8 & $7.31 \pm 0.70$ & $7.5(5.9-8.1)$ & \multirow{3}{*}{$<0.001^{\mathrm{a}^{*}}$} & $1-2^{c}:<0.001^{*}$ \\
\hline & 2 & 8 & $11.2 \pm 1.78$ & $11(9.2-15.1)$ & & $1-3^{c}: 0.321$ \\
\hline & 3 & 8 & $8.37 \pm 1.58$ & $8.1(6.1-10.9)$ & & $2-3^{c}: 0.002^{*}$ \\
\hline
\end{tabular}

\section{DISCUSSION}

Priapism represents a true erection physiology disorder. Although there are three different types, the most important form is ischemic priapism, which is high prevalence and causes quite detrimental effects (26). Ischemic priapism is an urological emergency characterized by persistent and painful erection in which cavernosal blood flow is little or no $(3,26)$. A clear etiological factor cannot be detected in $60 \%$ of cases with ischemic priapism. Hematologic diseases, oncological pathologies, neurological disorders and the use of antipsychotics, antidepressants, systemic or intracorporeal vasoactive agents are commonly known causes of priapism (2). The degree of destruction in ischemic priapism is directly associated with its duration. In patients with long-term untreatable priapism, permanent damage occurs in the smooth muscle fibers, which are deemed absolutely necessary for penile dynamics $(26,27)$. The durability of the penile tissues for the ischaemia occurring in penile corpus cavernosa is quite limited. In ischaemic priapism, ultrastructural alterations occur after 12 hours in smooth muscles, focal necrosis takes place after 24 hours and finally, necrosis and transformation of fibroblast-like cells occur after 48 hours (5). In present study, it was determined that dapsone, an antimicrobial agent, has a protective effect on ischaemia - reperfusion injury occurring after priapism.

Different treatment steps have been determined in ischaemic priapism. The primary objective of the treatment is to eliminate the compartment syndrome that occurs in the penile corpus cavernosa. The firstline treatment approach in ischaemic priapism is the aspiration of corporal blood. This intervention can be combined with saline irrigation. The success rate is reported to be approximately $30 \%$. The secondline treatment approach is the local intracavernosal sympathomimetic administration. It is thought that the success rate is up to $80 \%$ on average. The third treatment step is surgical shunts (2). Even if detumescence is successfully achieved, cases may present with several sexual dysfunctions, especially erectile dysfunction, in the later stages. El-Bahsanawy et al. (27) reported that only $43 \%$ of these cases were able to maintain their erectile function during long-term follow-up in a series of 35 cases with an average duration of 48 hours, which was directly linked to penile tumescence duration. Pal et 
al. (28) concluded in their study involving 19 patients that $66.7 \%$ of the cases of priapism which were successfully treated with intracorporeal phenylephrine injection and corporal aspiration had normal erectile functions in the follow-up. Kulmala et al. (29) reported in their largescale study of 124 cases that erectile dysfunction was observed in $39 \%$ of cases after priapism treatment. In the same study, the rate of erectile dysfunction was $8 \%$ in cases with a duration of less than 24 hours, while this rate was $78 \%$ in patients with a duration of more than 1 week. An important reason for encountering problems in the sexual life of the majority of the cases in long-term follow-ups after priapism can be explained by ischaemiareperfusion injury due to revascularization of penile tissues.

Ischaemia-reperfusion injury is observed at a very remarkable level in this clinical implication due to the fact that penile corpus cavernosa is reoxygenated quite quickly after the treatment of ischemic priapism $(30,31)$. Critical metabolic and structural changes occur in penile tissues due to lack of oxygenation during ischemic priapism. The function of cellular oxidative phosphorylation is reduced to low levels. This energy deficiency results in the inhibition of $\mathrm{Na}+\mathrm{K}+$-ATPase pump and intracellular sodium and calcium levels increase. This altered ion balance brings tissue edema and cytotoxic effect. This makes corporal tissues highly vulnerable to ischaemia reperfusion injury (4). During the ischemia period, a significant increase in the level of purine metabolites such as adenosine, hypoxanthine, xanthine and inosine is observed in the by-products of adenosine triphosphate (ATP) catabolism. These molecules accumulated in the tissue under ischemic conditions by using oxygen oxidants, which are abundant in the environment, become unstable and form intensely ROS by revascularization of the tissues $(32,33)$. It is extremely important to keep the duration of the ischaemia short, reducing the amount of reaction that low-energy molecules enter with oxygen and keeping ROS formation at controllable limits (6). On the other hand, ischaemia-reperfusion injury leads to both a local and a systemic acute inflammatory response characterized by neutrophil activation $(9,31)$. With this response, inflammatory cells become a second source for ROS. On the other hand, cystoxic molecules such as protease and myeloperoxidase released from activated neutrophils contribute to tissue damage. For all these reasons, anti-inflammatory molecules are thought to play an extremely important role in protecting cells against tissue damage in ischaemia-reperfusion damage (11). ROS levels are normally kept under control by antioxidant defense systems such as SOD, catalase and GSH-Px. These antioxidant systems are extremely ineffective in cases where oxygen flow is very rapid, such as the termination of priapism. In this context, it is evident that the use of molecules that show antioxidant efficacy has recently played a significant role in minimizing the harmful effects of ischaemia reperfusion injury (8). In this context, it has been biochemically and histopathologically demonstrated that Dapsone, which is a very strong antiinflammatory and antioxidant property used in the study, effectively regresses the ischemia-reperfusion damage in penile corpus cavernosa.

In previous experimental studies, the harmful effects of ischemia-reperfusion injury on penile corpus cavernosa tissue have been clearly demonstrated. Although numerous pharmacological agents such as curcumin, dipyridamole, melatonin, pentoxifylline, lycopene, quercetin have been shown to protect against tissue injury in different animal models, treatment routine protocols for ischaemia reperfusion injury in penile corpus cavernosa have not yet been developed across the world (4-9). In the priapism model where Yilmaz et al. evaluated ischaemia reperfusion injury, found that TAS decreased in experimental animals due to ischaemia reperfusion injury, while there was a significant increase in edema, necrosis and hemorrhage scores in penile tissue (4). Similarly, our study indicated a decrease in the level of antioxidant enzymes such as SOD and GSH-Px and in TAS due to ischemia reperfusion injury. Karagüzel et al. documented histopathologically that after ischaemiareperfusion injury, the endothelial cells covering the penile corpus cavernosa were severely damaged and quite a lot of tears were observed in tunica albuginea (5). In our study, it was observed that desquamation, edema and vasocongestion were detected high levels in penile tissues after ischaemia-reperfusion injury. The experimental study of the Ciftci et al. (8) reported that antioxidant defense systems such as SOD, catalase and GSH-Px were decreased in corporal ischaemia reperfusion injury, while TBARS (thiobarbituric acid reactive substances), an important marker of lipid peroxidation, was increased. Similarly, Uluocak et al. (6) reported that MDA level increased significantly in penile ischemia reperfusion injury. In our study, an increase in MDA and PC levels, the most important markers of lipid peroxidation and protein oxidation, was observed after ischaemia reperfusion injury. In another experimental study, Munarriz et al. (33) found that polymorphonuclear leukocyte infiltration was observed in penile corpus cavernosa with re-oxygenation of postischaemia, however, myeloperoxidase activity and lipid peroxidation increased. Similarly, in our study, it was observed that the inflammation scores in penile tissues increased significantly after ischemia reperfusion, and in our serum analysis, there was a dramatic increase in proinflammatory cytokines such as IL-1beta, IL-6 and TNF alpha. 
Dapsone was synthesized from p-nitro-thiophenol in the early 1900s and was heavily used in the chemical industry in the production of azo dyes during its initial use $(10,14)$. In the following periods, it has been discovered that this pharmacological agent plays a important role in maintaining the vital functions of the cell against tissue damage apart from antimicrobial property (16). This activity is performed via many different mechanisms. Inhibition of inflammation has a significant place among these pathways. Previous studies have revealed in great detail that dapsone has anti-inflammatory properties equivalent to nonsteroidal anti-inflammatory drugs (18). Dapsone demonstrates this effect in many different aspects. Dapson inhibits the activity of myeloperoxidase, which converts hydrogen peroxide into water and hypochlorous acid. In this way, it causes the hypochlorous acid level to be reduced, which leads to severe tissue damage $(10,18)$. On the other hand, this pharmacological agent stabilizes neutrophil lysosome, suppresses the expression of proinflammatory cytokines, neutrophil chemotaxis and neutrophil adherence function $(34,35)$.

Liang et al. (15) analyzed the efficacy of dapsone therapy in 79 cases with chronic spontaneous urticaria and experienced improvement in $78 \%$ of cases. Abe et al. also reported in their in vivo study examining the pharmacological effect of dapsone on cutaneous lupus erythematosus that this pharmacological agent produced an anti-inflammatory response by suppressing TNFalpha release from activated mononuclear cells (17). Dapsone, on the other hand, leads to a significant decrease in ROS levels by activating scavenging enzymes such as glutathione reductase, GSH-Px, SOD and catalase (12). In addition to its anti-inflammatory and antioxidant efficacy has been shown to have a strong anti-apoptotic properties in previous studies. Dapson demonstrates this effect by inhibiting both intrinsic apoptosis, which is triggered by the activation of the caspase in direct connection with the exposure of mitochondria to a very high amount of calcium, as well as extrinsic apoptosis, in which inflammatory mechanisms play a leading role (13).

The effects of dapsone on oxidative tissue damage on different tissues have been analyzed in detail in the previous years. Rios et al. (36) reported neuroprotective efficacy by reducing the infarction volume of dapsone therapy by more than $90 \%$ in the rat model in which they formed middle cerebral artery occlusion. In their experiment that resulted in intracranial kainic acid toxicity, Diaz-Ruiz et al. (16) demonstrated that dapsone prevents neuronal death of pyramidal cells by showing antioxidative and anticonvulsive properties. In our study, it was observed that dapson caused a significant increase in the level of antioxidant enzymes such as SOD and GSH-Px, which are a very important defense system against ischemia reperfusion damage after priapzm treatment. A similar experimental study also found that dapsone demonstrated neuroprotective activity in brain ischaemia reperfusion injury by lowering levels of nuclear factor erythroid 2-related factor 2 and reactive oxygen species, as evidenced with magnetic resonance images (37). In our study, a significant increase in TAS and a decrease in oxidative damage were observed after the dapsone treatment. Nezamoleslami et al. (18) observed that dapsone exhibited reno-protective properties on the kidney ischemia reperfusion injury and indicated that there was considerable evidence that this activity was carried out by modulating the inflammatory cascades. Similarly, in the experimental testicular torsion/detorsion model performed by Debjan et al. (11), a significant decrease in TNF-alpha levels of the rats applied dapsone was observed while a significant increase in SOD activity was indicated. In our study determined that TOS decreased to very low levels after dapsone treatment, while proinflammatory cytokine levels such as IL-1beta, 6 and TNF alpha were also reduced dramatically. In the study analyzing the efficacy of dapsone in cardiotoxicity caused by doxorubicin in rats, Sheibani et al. (12) found that dapsone significantly reduced oxidative stress and inflammation. The same study reported that it reversed the elevated cardiac enzyme levels due to cardiotoxicity and papillary muscle contractility. Although penile dynamics could not be evaluated in our study, it was found that edema, desquamation, hemorrhage and inflammation scores that increased due to ischemiareperfusion damage in the penile corpus cavernosa after dapsone treatment significantly regressed.

The main limitation of our study is to evaluate only the early effects of dapsone treatment after priapism. In our study, dapsone was administered only in a single dose, and its long-term effects could not be demonstrated. Although previous studies have reported that dapsone does not have a dangerous side effect profile, our study failed to document the changes that this pharmacological agent may potentially cause in penile corpus cavernosa in healthy experimental animals. Finally, penile dynamics could not be revealed and immunohistochemical analyses could not be presented due to the technical incapacity of our laboratory conditions.

\section{CONCLUSION}

In the light of the data obtained in our study, we are in the opinion that dapsone therapy can be considered as an alternative approach to minimise ischaemia-reperfusion injury in penile corpus cavernosa during priapism. Although our study adds a new function in the treatment approach of priapism with this use of dapsone, it is 
essential to elaborate the molecular mechanism of this activity and determine the dose curves. Furthermore, our study was based solely on the experimental priapism model and our results should be validated by prospective, randomized and controlled clinical trials in the future.

\section{ETHICAL DECLARATIONS}

Ethics Committee Approval: The study was carried out with the permission of Tokat Gaziosmanpaşa University Animal Studies Ethics Committee (Date: 08.04.2021, Decision No: 2021-HADYEK-06).

Referee Evaluation Process: Externally peer-reviewed.

Conflict of Interest Statement: The authors have no conflicts of interest to declare.

Financial Disclosure: The authors declared that this study has received no financial support.

Author Contributions: All of the authors declare that they have all participated in the design, execution, and analysis of the paper, and that they have approved the final version.

\section{REFERENCES}

1. Reddy AG, Alzweri LM, Gabrielson AT, Leinwand G, Hellstrom WJG. Role of Penile Prosthesis in Priapism: A Review. World J Mens Health 2018; 36: 4-14.

2. Tay YK, Spernat D, Rzetelski-West K, Appu S, Love C. Acute management of priapism in men. BJU Int 2012; 109: 15-21.

3. Ridgley J, Raison N, Sheikh MI, Dasgupta P, Khan MS, Ahmed K. Ischaemic priapism: A clinical review. Turk J Urol 2017; 43: 1-8.

4. Yılmaz Y, Taken K, Atar M, Ergün M, Söylemez H. Protective effect of curcumin on priapism and ischemia-reperfusion injury in rats. Eur Rev Med Pharmacol Sci 2015; 19: 4664-70.

5. Karaguzel E, Bayraktar C, Kutlu O, et al. The possible protective effects of dipyridamole on ischemic reperfusion injury of priapism. Int Braz J Urol 2016; 42: 146-53.

6. Uluocak N, Atılgan D, Erdemir F, et al. An animal model of ischemic priapism and the effects of melatonin on antioxidant enzymes and oxidative injury parameters in rat penis. Int Urol Nephrol 2010; 42: 889-95.

7. Erdemir F, Firat F, Markoc F, et al. The effect of pentoxifylline on penile cavernosal tissues in ischemic priapism-induced rat model. Int Urol Nephrol 2014; 46: 1961-7.

8. Ciftci O, Oguz F, Beytur A, Polat F, Altıntas R, Oguzturk H. Lycopene prevents experimental priapism against oxidative and nitrosative damage. Eur Rev Med Pharmacol Sci 2014; 18: 3320-5.

9. Cevik Ö, Cadırcı S, Sener TE, et al. Quercetin treatment against ischemia/reperfusion injury in rat corpus cavernosum tissue: a role on apoptosis and oxidative stress. Free Radic Res 2013; 47: 683-91.

10. Koca R. Dapsone. Turkiye Klinikleri Dermatology 2014; 7: 43-8.

11.Dejban P, Rahimi N, Takzare N, Jahansouz M, Haddadi NS, Dehpour AR. Beneficial effects of dapsone on ischemia/ reperfusion injury following torsion/detorsion in ipsilateral and contralateral testes in rat. Theriogenology 2019; 140: 136-42.

12.Sheibani M, Nezamoleslami S, Faghir-Ghanesefat H, Hossein Emami A, Dehpour AR. Cardioprotective effects of dapsone against doxorubicin-induced cardiotoxicity in rats. Cancer Chemother Pharmacol 2020; 85: 563-71.
13. Ríos C, Orozco-Suarez S, Salgado-Ceballos H, et al. AntiApoptotic Effects of Dapsone After Spinal Cord Injury in Rats. Neurochem Res 2015; 40: 1243-51.

14. Wozel G, Blasum C. Dapsone in dermatology and beyond. Arch Dermatol Res 2014; 306: 103-24

15.Liang SE, Hoffmann R, Peterson E, Soter NA. Use of Dapsone in the Treatment of Chronic Idiopathic and Autoimmune Urticaria. JAMA Dermatol 2019; 155: 90-5.

16.Diaz-Ruiz A, Mendez-Armenta M, Galván-Arzate S, et al. Antioxidant, anticonvulsive and neuroprotective effects of dapsone and phenobarbital against kainic acid-induced damage in rats. Neurochem Res 2013; 38: 1819-27.

17. Abe M, Shimizu A, Yokoyama Y, Takeuchi Y, Ishikawa O. A possible inhibitory action of diaminodiphenyl sulfone on tumour necrosis factor-alpha production from activated mononuclear cells on cutaneous lupus erythematosus. Clin Exp Dermatol 2008; 33: 759-63.

18. Nezamoleslami S, Sheibani M, Jahanshahi F, Mumtaz F, Abbasi A, Dehpour AR. Protective effect of dapsone against renal ischemiareperfusion injury in rat. Immunopharmacol Immunotoxicol 2020; 42: 272-9.

19. Esterbauer H, Cheeseman KH. Determination of aldehydic lipid peroxidation products: malonaldehyde and 4-hydroxynonenal. Methods Enzymol 1990; 186: 407-21.

20.Levine RL, Garland D, Oliver CN, et al. Determination of carbonyl content in oxidatively modified proteins. Methods Enzymol 1990; 186: $464-78$

21. Sun Y, Oberley LW, Li Y. A simple method for clinical assay of superoxide dismutase. Clin Chem 1988; 34: 497-500.

22.Paglia DE, Valentine WN. Studies on the quantitative and qualitative characterisation of erythrocyte glutathione peroxidase. J Lab Clin Med 1967; 70: 158-69.

23.Erel, O. A novel automated method to measure total antioxidant response against potent free radical reactions. Clinical Biochemistry 2004; 37: 112-9.

24.Erel O. A new automated colorimetric method for measuring total oxidant status. Clinical Biochemistry 2005; 38: 1103-11.

25. Senturk GE, Erkanli K, Aydin U, et al. The protective effect of oxytocin on ischemia/reperfusion injury in rat urinary bladder. Peptides 2013; 40: 82-8.

26. Levey HR, Segal RL, Bivalacqua TJ. Management of priapism: an update for clinicians. Ther Adv Urol 2014; 6: 230-44.

27.El-Bahnasawy MS, Dawood A, Farouk A. Low-flow priapism: risk factors for erectile dysfunction. BJU Int 2002; 89: 285-90.

28. Pal DK, Biswal DL, Ghosh B. Outcome and erectile function following treatment of priapism: An institutional experience. Urol Ann 2016; 8: 46-50.

29. Kulmala RV, Lehtonen TA, Tammela TL. Preservation of potency after treatment for priapism. Scand J Urol Nephrol 1996; 30: 3136

30.Sener G, Paskaloğlu K, Sehirli AO, Dülger GA, Alican I. The effects of melatonin on ischemia-reperfusion induced changes in rat corpus cavernosum. J Urol 2002; 167: 2624-7.

31.Wu MY, Yiang GT, Liao WT, et al. Current Mechanistic Concepts in Ischemia and Reperfusion Injury. Cell Physiol Biochem 2018; 46: 1650-67.

32. Taati M, Moghadasi M, Dezfoulian O, Asadian P. Effects of ghrelin on testicular ischemia/reperfusion-1nduced injury. Acta Med Iran 2016; 54: 32-8

33. Munarriz R, Park K, Huang YH, et al. Reperfusion of ischemic corporal tissue: physiologic and biochemical changes in an animal model of ischemic priapism. Urology 2003; 62: 760-4.

34. Salehzadeh F, Jahangiri S, Mohammadi E. Dapsone as an alternative therapy in children with familial mediterranean Fever. Iran J Pediatr 2012; 22: 23-7. 
35.Lee JH, Choi SH, Lee CJ, Oh SS. Recovery of dementia syndrome following treatment of brain inflammation. Dement Geriatr Cogn Dis Extra 2020; 10: 1-12.

36. Ríos C, Nader-Kawachi J, Rodriguez-Payán AJ, Nava-Ruiz C. Neuroprotective effect of dapsone in an occlusive model of focal ischemia in rats. Brain Res 2004; 999: 212-5.

37.Diaz-Ruiz A, Roldan-Valadez E, Ortiz-Plata A, et al. Dapsone improves functional deficit and diminishes brain damage evaluated by 3 -Tesla magnetic resonance image after transient cerebral ischemia and reperfusion in rats. Brain Res 2016; 1646: 384-92. 